LINGUACULTURE 1, 2018

\title{
CULTURAL MARKERS OF ANGLO-SAXON CULTURAL CONCEPTS: A LINGUO-STATISTICAL APPROACH
}

\author{
NADIA YESYPENKO*
}

Yuriy Fedkovych National Univeristy, Chernivtsi, Ukraine

\begin{abstract}
This article addresses the notion of a cultural concept with reference to the British culture. It focuses in particular on the concept typology, with the assumption that a discussion of concept types and their meanings (as notional components in the concept structure) can enhance the understanding and appreciation of conceptual and associative meaning to reveal the concept's cultural elements (markers). The discussion takes its general conceptual orientation from the approach that considers a concept as a verbalized mental entity whereby the unit of analysis is the sentence embracing lexical units that stand for a cultural concept. This is a functional view of the concept's verbal embodiment, the tenets of which are contained in cognitive grammar. From a broader perspective, the article distinguishes the concept's content through the associative use of a lexical concept with the collocated lexemes (nouns, verbs and adjectives) in a sentence, then proceeds to deal with the concept GENTLEMANLINESS and its cultural markers in the British novels of the $18^{\text {th }}$ $20^{\text {th }}$ centuries. Ultimately, the linguo-statistical method of associative analysis finds in texts of fiction ten cultural associative markers of the concept in the $18^{\text {th }}$ century: nobility of birth, wealth, professional or business activities, appearance, emotions, surrounding of a gentleman, time, leisure and entertainment, symbols of gentlemanliness, traveling; seven associative markers of the concept are found in the novels of the $19^{\text {th }}$ century: noble origin and social status, well-being, professional or business activities, appearance, emotions, surrounding of a gentleman, time; six cultural markers of GENTLEMANLINESS are distinguished in the $20^{\text {th }}$ century novels: high social ranking, being self-organized, occupation, appearance, traits of character, surrounding of a gentleman. From the discussion, conclusions about the involution of the concept of GENTLEMANLINESS are drawn.
\end{abstract}

Keywords: cultural concept; lexical concept; conceptual sphere; associative analysis; gentlemanliness.

n.yesypenko@chnu.edu.ua 


\section{INTRODUCTION}

The extrapolation of the cognitive paradigm to literary texts of a certain cultural society allows to identify cultural concepts that form a conceptual sphere of that cultural society and to describe the linguistic means of their representation. The conceptual sphere is understood by some authors as a set of semantic, conceptual and associative characteristics that actualize constituent concepts of the conceptual sphere. V. Evans considers a conceptual system (sphere) as the repository of concepts available to a human being. The repository constitutes a structured and organised inventory which facilitates categorisation and conceptualisation. Each concept in the conceptual system can be encoded and externalised via language. Concepts encoded in language take a modality-specific format known as a lexical concept. Cognitive linguists assume that language reflects the conceptual system and thus can be employed in order to investigate conceptual organisation (Evans 2007, 38).

The conceptual sphere is influenced by two groups of factors: linguistic and extra-linguistic. Linguistic factors determine the scope of verbalization of a certain cognitive structure (a concept) as well as a set of language units ensuring the implementation of the cognitive structure resulting from the interaction of extra-linguistic factors. Extra-linguistic factors embrace the individual human experience (physical and physiological), cultural environment, socio-cultural features of a certain society, experience of a language community and features of its historical development.

The conceptual sphere tightly interweaves with values of a certain cultural ethic society. T. Radbil states, that cultural concepts as constituents of the conceptual sphere also belong to the sphere of values which directs self-awareness and the development of a cultural ethnic group (Radbil 234). Cultural concepts can be distinguished according to the values of a social status bearer. V. Karasyk believes that separate social groups are quite distinguishable in every society; representatives of social groups have different conceptual spheres. Ethnic traits are not unbeatably marked and isolated, but they are embedded in social interaction. There exists a social ethnic self-awareness of an individual which creates cultural concepts (Karasik 118). It is hard to postulate that English white-collar workers (e.g., bankers) and English blue-collar workers (e.g., builders) speak different languages, as their conceptual spheres frequently intersect in notions verbalized by means of common vocabulary, though there are concepts in their conceptual spheres that bear no resemblance. Thus, three groups of cultural concepts are recognized: ethnic-cultural, socio-cultural and individual-cultural. The conceptual sphere includes concepts valued and recognized by the whole ethnic culture representatives, by separate groups 
within a socio-cultural society and by individuals who are bearers of a certain culture.

In our further analysis we will proceed from the following assumptions:

1. A cultural concept is a dynamic component of culture.

2. Cultural concepts form the conceptual sphere which is understood as the repository of mental culturally marked entities common for bearers of a certain culture.

As suggested above, language is inextricably linked with culture, but the question remains: does the language an individual speaks reflect his/ her culture or is his/ her world view determined or affected by language? The Sapir-Whorf hypothesis of the early $20^{\text {th }}$ century would argue the latter: individuals make sense of the world by organizing it into some sort of order by naming things, using language. Thus, the view of the world is limited or shaped by the language individual use. Sapir says:

The fact of the matter is that the real world is to a large extent unconsciously built upon the language habits of the group. No two languages are ever sufficiently similar to be considered as representing the same social reality. The worlds in which different societies live are distinct worlds, not merely the same world with different labels attached. We see and hear and otherwise experience very largely as we do because the language habits of our community predispose certain choices of interpretation (Sapir 92)

Whorf adds:

We cut nature up, organize it into concepts, and ascribe significances as we do largely because we are parties to an agreement to organize it in this way - an agreement that holds throughout our speech community and is codified in the patterns pf our language (Whorf 41)

If literally considered, there are two basic principles in the Sapir-Whorf theory: linguistic determinism (an individual's thinking is determined by language) and linguistic relativism (individuals who speak different languages see and make sense of the world differently).

While following the theory, it would be difficult to translate thoughts, feelings and understanding of the world into another language so that the speakers of that language see it in exactly the same way. Some theorists suggest that meaning will be changed as we repeat, or reformulate, statements to one another, even within our own language. If we paraphrase what someone says, then we may change the statement, colouring it with our own meaning. However, other theorists hold that we can always say what we want to in any language, that everything can be translated from one language into another. Karl Popper, the philosopher, believed that that there is 
'essential truth' in every sentence which can be translated, and that even totally different languages are not untranslatable (Popper 1970).

Although we can agree that, in its original form, the Sapir-Whorf hypothesis is a little extreme, there are important statements for our further study:

1. The outlook of the individual on life is influenced by the language s/he speaks.

2. The way the individual speaks is influenced by his/ her outlook on life.

3. The social context influences the way the individual uses language.

In considering these three points, we are reminded of Michael Hoey's theory of Lexical Priming, where the initial experience of a lexical item 'primes' the individual for meaning in his/ her subsequent encounters with the item. (Hoey 2005)

\section{THEORETICAL FRAMEWORK AND METHODS}

So far, linguistic and cultural studies have developed a number of approaches to identifying the structure of concepts and their embodiment in texts. Most known approaches belong to L. Wittgenstein, E. Rosch, Ch. J. Fillmore, R. Langacker, Ch. Peacocke, G. Lakoff and M. Johnsen. Ch. Peacocke (1995) argues for an interactive relationship between philosophical and psychological theories of concepts, and he plots many connections with work in cognitive psychology. George Lakoff and Mark Johnsen consider that the conceptual system is fundamentally metaphorical in nature and "our concepts structure what we perceive, how we get around in the world, and how we relate to other people" (Lakoff and Johnsen 4); Ch. J. Fillmore (1976) who does his research on the nature of framing in thought and language states that we think, largely unconsciously, in terms of conceptual frames - mental structures that organize our thought; R. Langacker who in his book Foundations of Cognitive Grammar, Vol 1 states that "the building blocks of grammar are minimal symbolic units, morphemes" (Langacker 1987, 97), which he refers to as 'predicates' according to their semantic pole, and he views linguistic expressions as predications. In their turn, all predications are characterized relative to one or more cognitive domains (Langacker 1987, 98). Thus, grammar may be deconstructed into patterns that come together in order to represent concepts. L. Wittgenstein recognises 'family resemblance' as the thread that constructs the fabric of a concept. He stresses the difference that takes place within categories: "For if you look at them you will not see something common to all, but similarities, relationships, and a whole series of them" (Wittgenstein 66). The context is 
required to recognize how the word is being used. Wittgenstein calls the shifting of meaning 'language games', and this idea helped shape prototype theory as developed by E. Rosch. Rosch's prototype theory of concepts decides membership in a category through possession of particular properties, but group membership does not require possession of all qualities - just enough for the fabric of the concept to hold together. Concepts are defined "only in actual situations in which they function as participating parts of the situation rather than as either representations or as mechanisms for identifying options” (Rosch 61).

In modern cognitive linguistics a concept is often understood as "the fundamental unit of knowledge central to categorisation and conceptualisation” (Evans 2006, 31). Concepts inhere in the conceptual system through the perceptual experience with the help of a process termed 'perceptual meaning analysis'.

Concepts can be encoded in a language-specific format known as the 'lexical concept'. Any lexical concept has a unique 'lexical profile'. A lexical profile relates to the range of semantic arguments and grammatical constructions with which a given lexical concept conventionally co-occurs and which forms part of the mental knowledge associated with a given lexical concept. In such a way the lexical profile serves as a dominant means of distinguishing lexical concepts that are conventionally associated with the same form. A lexical concept's lexical profile is made up of two sorts of information: the semantic arguments with which a given lexical concept can collocate and the grammatical patterns in which a given lexical concept occurs.

Concepts are quite stable cognitive entities, but they are constantly modified by ongoing episodic and recurrent experiences that people gain through social activities, cultural interactions within one ethnic group or many groups. Cultural experience absorbs cultural markers that are events or facets of society that illustrate or reveal cultural or societal norms and shifts in those norms. These cultural markers may be the result of various conditions including location, gender, race, history, nationality, language, religious beliefs, ethnicity, aesthetics and even food. Language is an important cultural marker, as it lexicalizes unique knowledge units (concepts) that promote connections and roots to cultural histories. Embodied through language, cultural concepts reflect values, social norms and self-identification of people organizing them into a separate nation.

As for the definition of a term 'cultural concept', it is often used to refer to a concept's subtype being a culturally specific mental representation (Stepanov 2004, 40). Some cognitive linguists assert that every concept is culturally specific (Radbil 234), some linguists extend the term emphasizing on lexicalization of the concept and suggest a notion of a 'linguo-cultural 
concept' (Vorkachev 2003). In our research we use the term 'cultural concept', though we agree that every concept incorporates cultural and evaluative (axiological) elements in its structure.

The structure of a cultural concept includes the image, associative, notional, axiological and etymological components (Kononova 91-104). The image component of a concept may include a visually-perceptible representation or a combination of conceptual metaphors deduced from the collocations of the words, lexicalising the concept in language. The associative component of a cultural concept is formed by the dominant associative relations of the language units representing the concept. The notional component of a concept has the intersection zones with the associative one as it can be drawn from the dominant associative links of a concept, however, the genetic features of a concept constitute a basic part of the notional component. The axiological component of a concept, according to G. G. Slyshkin, can be decomposed into two measurable aspects: relevance and evaluation. The evaluative aspect is reflected in the meaning of a language unit, lexicalising a concept or in combinations of units with the emotive meaning. The aspect of relevance is revealed through realization of a concept in different types of discourse (Slyshkin 2000). The etymological component of a concept is determined by the inner form of the word; it serves as additional motivation to its axiological component (Stepanov 2004).

The main attention in the study of cultural concepts lexicalized in literary texts will be given to the associative component as it is subjected to verification by language facts and influenced by the discursive conditions to a great degree.

The goal of our study is to identify cultural markers in the concept GENTLEMANLINESS actualization in English literary texts of the $18^{\text {th }}-$ $20^{\text {th }}$ century on the results of the lexeme gentleman concordance, coocurrence and collocations in the lexical context. We rely on G. Altmann's (2010) associative analysis based on co-occurrences of some exactly defined basic entities in a priori defined environments, V. V. Levickij's (2004) theory of collocations and adjoining words which amplify the lexical concept by bringing in their additional senses and emotional load to the concept sphere, J. R. Firth's (1957) study of the context-dependent nature of meaning with his notion of 'context of situation'. These approaches offer invaluable insights into a lexicalized concept via the lexemes' usage and links within definite lexical environment. By exploring these focal points in depth we may be able to show notions related to British culture that reveal a structure of the lexical concept in question. These approaches are also based on computations which assure objective results of the study. 
We put forward a hypothesis that extending our research to the lexical context we will notice that there is considerable diversity in cultural associations with the notion of 'gentlemanliness'.

We claim that in order to make sense of the world around us, a writer must be cognitively equipped with some image schemes of different world phenomena. The image schemes are mental constructs available to human cognition. We could further conclude that these schemes are employed for the conceptualization of such phenomenon as GENTLEMANLINESS. The conceptualization of this phenomenon is based on the author's experience associated with a gentleman and the characteristics of a gentleman determined by a given time period and culture. This being the case, we should also find some hints at that in language, and it can be assumed that also image schemes should leave traces in the lexicalization of the respective concept. In order to find such traces, one of the things to do is to consider all the adjoining words. These words can have a straightforward connection to image schemes combined in GENTLEMANLINESS or they are closely linked with the phenomena related to a gentleman.

Once we speak of the adjoining words as the bearers of the concept's additional meaning, we can't but mention that the adjoining words evolve associative meanings of the concept that will or will not correspond to the conceptual meaning of lexeme gentleman. The conceptual meaning can be represented as a set of distinctive features described as semes. The operant features for "gentleman" that we find in The Living Webster Encyclopedic Dictionary of the English Language are: "a man who is polite and well educated, who has excellent manners and always behaves well; used to address or refer to a man, especially sb you do not know; used to address or refer to a male member of a legislature; a man from a high social class, especially one who does not need to work" (The Living Webster Encyclopedic Dictionary of the English Language 459).

Consider the following sentence:

... let us, like gallant gentlemen, exchange polite attentions in the meantime. Permit me to take the liberty of calling for my wife (W. Collins The Woman in White).

Gentleman $\longrightarrow$ a man who has excellent manners and always behaves well.

Associative meaning describes a composite of meanings drawn on certain mental connections expressed by language means. Such connections are based on the contiguities of real-world experience of the writer and the real-world values a writer associates with the concept. A real-world value is perceived in terms of socio-cultural principles, norms and rules.

Associative meaning refers to the sense a lexeme may acquire on account of the meanings of lexemes that tend to co-occur in similar lexical 
environment (a sentence or a paragraph). This becomes apparent when we consider the following sentence:

Mr. Bingley was good looking and gentlemanlike; he had a pleasant countenance, and easy, unaffected manners. His brother-in-law, Mr. Hurst, merely looked the gentleman; but his friend Mr. Darcy soon drew the attention of the room by his fine, tall person, handsome features, noble mien... (J. Austen Pride and Prejudice)

The associative meaning of a 'gentleman' includes "easy, unaffected manners", but if we proceed with the adjoining words used in the further sentences in the paragraph, we will see that a 'gentleman' is a good-looking man bearing "handsome features" and "noble mien".

The case at hand shows that the associative meaning of the concept is wider than the conceptual one. The conceptual meaning is stable and invariable since it can be represented by means of a finite set of symbols, by their semantic features or semantic rules. In contrast, the associative meaning is variable since it owes its validity to social and cultural factors.

Though associative meaning refers to the ideal mental (cognitive) realm, the methods of research appropriate for lexical concept realization should not rest on the researcher's intuitive conclusions. They require a corpusbased approach that allows quantitative methods to measure a degree of association between a concept and adjoining words revealing a whole spectrum of the meanings hidden in the concept of GENTLEMANLINESS.

\section{DISCUSSION}

British linguist J. R. Firth drew attention to the crucial role of the lexical context which surrounds the lexeme, when we analyze its meaning. He said: "You shall know a word by the company it keeps." (Firth 11) This can be seen from the concordance. It shows the occurrence of gentleman with enough context before and after to see how this item is being used in each. The various meanings of the lexical concept begin to appear when we examine the collocations or adjoining words. There are two useful ideas in the study of a concept through lexical contexts: there is a central lexeme or node, surrounded by lexemes in the sentences - the span within which the search of collocations takes place. The span in our examples is quite large, allowing 10 or so words on either side of the node. We look at the lexemes which are immediately adjacent to a node and at those which fall withing three or four places on each side of it. Computational help is essential in this case.

To carry out an associative analysis we follow Altmann's approach to define exact probabilities of co-occurences. Associative analysis is based on 
co-occurrences of the central lexeme gentleman in selected lexical environments. We use lemmas whose environment is sentences in the text of a novel. The analysis tries to find overt or covert associations and computes the probability of lemmas to occur simultaneously in a definite text. Each novel is analyzed separately. The formula used for computation is as follows:

$$
P(X \geq x)=\sum_{j=x}^{\min (M, n)} \frac{\left(\begin{array}{l}
M \\
x
\end{array}\right)\left(\begin{array}{c}
N-M \\
n-x
\end{array}\right)}{\left(\begin{array}{l}
N \\
n
\end{array}\right)}
$$

where $N$ is the number of sentences in the text, $M$ is the frequency of the lexeme gentleman in the text, $n$ is the occurence of the most frequent noun/ verb/adjective, $x$ is a number of sentences where gentleman and the most frequent noun/ verb/ adjective occur simultaneously. The resulting number is the probability that gentleman and a noun/ verb/ adjective occurred together in the text. The smaller this number, the greater the association between them. Tables 1, 2, and 3 show lexemes, associated with gentleman in the novels of British writers.

Table 1 Words associated with gentleman in the novels of the $18^{\text {th }}$ century

\begin{tabular}{|c|c|c|c|c|c|}
\hline Noun & Probability & Noun & Probability & Noun & Probability \\
\hline time & 0.000271 & son & 0.018076 & talent & 0.036929 \\
\hline town & 0.003926 & afternoon & 0.036929 & fortune & 0.044987 \\
\hline name & 0.01209 & birth & 0.036929 & $\begin{array}{c}\text { man of } \\
\text { honour }\end{array}$ & 0.044987 \\
\hline board & 0.012274 & bravery & 0.036929 & body & 0.045067 \\
\hline fashion & 0.012274 & coat & 0.036929 & dinner & 0.045067 \\
\hline post-chaise & 0.012274 & dance & 0.036929 & profession & 0.045067 \\
\hline subject & 0.012274 & matter & 0.036929 & suspicion & 0.045067 \\
\hline traveller & 0.012274 & neighbourhood & 0.036929 & terror & 0.045067 \\
\hline lady & $1.9 \mathrm{E}-05$ & education & 0.036929 & & \\
\hline Verb & Probability & Verb & Probability & Verb & Probability \\
\hline walk & 0.000757 & desire & 0.014069 & let & 0.020649 \\
\hline visit & 0.001334 & look & 0.015825 & speak & 0.020829 \\
\hline see & 0.00589 & know & 0.017685 & think & 0.02329 \\
\hline hear & 0.007026 & say & 0.020412 & return & 0.040557 \\
\hline come & 0.044242 & travel & 0.045067 & continue & 0.04929 \\
\hline be & $5.73 E-10$ & & & & \\
\hline Adjective & Probability & Adjective & Probability & Adjective & Probability \\
\hline poor & 0.000314 & country & 0.012274 & English & 0.017692 \\
\hline
\end{tabular}




\begin{tabular}{|c|c|c|c|c|c|}
\hline learned & 0.001352 & elderly & 0.012274 & kind & 0.017692 \\
\hline fine & 0.00391 & fair & 0.012274 & strange & 0.017692 \\
\hline ill & 0.004075 & neighbouring & 0.012274 & French & 0.019412 \\
\hline wounded & 0.019462 & old & $1.34 \mathrm{E}-23$ & pretty & $5.65 \mathrm{E}-06$ \\
\hline
\end{tabular}

The lexemes demonstrating an associative link with the noun gentleman in the analyzed texts can be grouped into ten cultural associative markers of the concept in the $18^{\text {th }}$ century novels:

- nobility of birth (e.g. birth, son, man of honour, lady);

- wealth (e.g. fortune);

- professional or business activities (e.g. profession);

- appearance (e.g. coat, fashion, body, fine, pretty, elderly, fair);

- emotions (e.g. suspicion, strange, desire);

- surrounding of a gentleman (e.g. neigbourhood, town, neighbouring);

- time (e.g. afternoon, time);

- leisure and entertainment (e.g. dance, dinner, visit, walk);

- features of gentlemanliness (e.g. bravery, education);

- traveling (e.g. traveler, come, return, travel, post-chaise).

Some cultural markers of the gentleman were passed over from the $16^{\text {th }}$ $17^{\text {th }}$ centuries, when the gentlemen were a social group of the British gentry taking the position below the baronets, knights and esquires. The gentry was divided from the yeoman farmers by wealth, rank and social status, and equally from the nobility and great landowners. By the $17^{\text {th }}$ century, the gentry could be considered as composed of four orders of landowners ranking immediately below the peerage: 1) the first were the baronets, holders of an inheritable title first created in 1611 in order to fill the gap between a small body of peers and the much more numerous knights; 2) baronets ranked above the ancient orders of knights that after 1611 constituted the second stratum of the gentry. The dubbing of knights goes back beyond the Norman Conquest; 3) the third rank of 'esquire' also had medieval and military origin. The use of the term gradually widened to include the sons of peers and the first born sons of baronets and knights, and in the course of time the esquire or squire came to rank above the gentlemen; 4) the gentlemen. When the term first appeared in Chaucer's Canterbury Tales in the $12^{\text {th }}$ century it was used ironically to describe "parfit, gentil knight”. The chivalrous traits were the main characteristics of the term. The $15^{\text {th }}$ century was the time when the term 'gentleman' referred to highranking individuals who were manly 'landowners'. In the subsequent centuries, the $16^{\text {th }}$ and $17^{\text {th }}$ the 'gentlemen' were a social group in the English gentry just below the baronets, knights and esquires.

In the $18^{\text {th }}$ century not only nobility of birth, but prestigious professions and wealth could turn people from the lower classes into gentlemen. An 
upper class social status allowed the gentleman to be well-educated, to follow gentleman's pursuits like visits, dances and music, and at the same time to keep to high moral values.

Table 2 Words associated with gentleman in the novels of the $19^{\text {th }}$ century

\begin{tabular}{|c|c|c|c|c|c|}
\hline Noun & Probability & Noun & Probability & Noun & Probability \\
\hline satisfaction & 0.006761 & family & 0.036911 & rank & 0.036911 \\
\hline business & 0.008637 & finger & 0.036911 & subject & 0.036911 \\
\hline creature & 0.012261 & land & 0.036911 & estate & 0.045033 \\
\hline name & 0.027572 & laughing & 0.036911 & intention & 0.045033 \\
\hline lady & 0.034792 & month & 0.036911 & matter & 0.045033 \\
\hline appearance & 0.036911 & point & 0.036911 & & \\
\hline Adjective & Probability & Adjective & Probability & Adjective & Probability \\
\hline old & $1.36 \mathrm{E}-18$ & noble & 0.034126 & gentlemanly & 0.036911 \\
\hline pale & $6.85 \mathrm{E}-07$ & good & 0.036575 & London & 0.036911 \\
\hline young & $5.23 \mathrm{E}-06$ & acquainted & 0.036911 & medical & 0.036911 \\
\hline strange & 0.003746 & deceased & 0.036911 & pleasant & 0.036911 \\
\hline gentlemanlike & 0.004069 & elderly & 0.036911 & spirited & 0.036911 \\
\hline present & 0.01554 & fat & 0.036911 & stout & 0.036911 \\
\hline close & 0.04494 & & & & \\
\hline Verb & Probability & Verb & Probability & Verb & Probability \\
\hline call & 0.004069 & end & 0.012261 & exchange & 0.036911 \\
\hline expect & 0.008604 & smile & 0.019429 & notice & 0.036911 \\
\hline be & 0.026232 & read & 0.042014 & & \\
\hline
\end{tabular}

The associative analysis distinguishes the following seven cultural markers of the concept in the novels of the $19^{\text {th }}$ century:

- noble origin and social status (e.g. family, rank, name, lady);

- wellbeing (e.g. land, estate);

- professional or business activities (e.g. business);

- appearance (e.g. old, pale, young, gentlemanlike, noble, fat, stout);

- emotions (e.g. intention, satisfaction, spirited, smile);

- surrounding of a gentleman (e.g. creature);

- time (e. g. month, point).

In the $19^{\text {th }}$ century the developments in economy and science, and expanding of the British Empire had a great impact on the social and moral features of the gentleman. The gentleman was more frequently engaged in business to guarantee his independent wealth and status, he strived to develop personal qualities in intellect, manners and morals. The nobility of birth appeared to be less characteristic of the gentleman in the $19^{\text {th }}$ century; the focus was on the manners and behavior of the gentleman. Gentlemanliness became important as it was a moral not just a social category. 
Table 3 Words associated with gentleman in the novels of the 20th century

\begin{tabular}{|c|c|c|c|c|c|}
\hline Noun & Probability & Noun & Probability & Noun & Probability \\
\hline lady & 0.000309 & aristocrat & 0.036616 & glasses & 0.036616 \\
\hline nature & 0.017289 & fashion & 0.036616 & order & 0.036616 \\
\hline trouble & 0.036616 & $\begin{array}{c}\text { gentleman- } \\
\text { farmer }\end{array}$ & 0.036616 & work & 0.044487 \\
\hline Verb & Probability & Verb & Probability & Verb & Probability \\
\hline pay & 0.002416 & aid & 0.036616 & enter & 0.036616 \\
\hline Adjective & Probability & Adjective & Probability & Adjective & Probability \\
\hline noble & $4.57 \mathrm{E}-06$ & literary & 0.036616 & private & 0.036616 \\
\hline black & 0.036616 & named & 0.036616 & young & 0.037047 \\
\hline
\end{tabular}

The smallest number of cultural markers of GENTLEMANLINESS is distinguished in the novels of the $20^{\text {th }}$ century:

- high social ranking (e.g. aristocrat, fashion);

- being self-organized (e.g. order, pay);

- occupation (e. g. gentleman-farmer, work);

- appearance (e.g. young, glasses);

- traits of character (e.g. noble);

- surrounding of a gentleman (e. g. nature).

All kinds of scientific, philosophical and sociological developments had a great influence in the formation of the gentleman's image in the $20^{\text {th }}$ century. As a result of these advances, the gentleman's superiority in terms of morality and manner rather than birth and wealth has been considered in the construction of his portrait in the novels of this period. Only six cultural markers revealed by the associative analysis illustrate that GENTLEMANLINESS despite of being in existence in the British cultural sphere as a leading concept in the $18^{\text {th }}-19^{\text {th }}$ centuries underwent its involution in the $20^{\text {th }}$ century.

\section{CONCLUSIONS}

The concept is a spectrum containing many cultural markers: their least common denominator is that they all involve a man's actions in society as a measure of his gentlemanliness. Manners, breeding, life-style, feelings in action, honor, honesty, integrity, generosity, courtesy, truthfulness, helpfulness and many more are shaped and formed by the cultural environment. The associative meaning of the concept changes within centuries. It reflects changes in the class system related to the expansion of the empire, the changes in the education system in Britain, the shifts in the 
people's moral and ethic values and social behavior. The greatest number of associative cultural markers revealed in the novels of the $18^{\text {th }}$ century proves that the gentleman was a central figure in culuture of that period bearing his status, power, self-assertion, and self-cultivation. The process of moralization has been going on since the $18^{\text {th }}$ century and the historical significance of the upper class was clearly traced. The $19^{\text {th }}$ century viewed the expansion of the British Empire, the rise of the British economy and the rapid advances in the industrial technology in England and abroad. The need to construct a ruling class for the empire by the aristocrats and the lower class's desire to switch their status or to get better standard of living activated the demand for gentlemen.

Although the gentleman retained his social class implications in the novels of the $20^{\text {th }}$ century, the associative cultural markers point out some 'gentlemanly' moral qualities. On the one hand, in the last two hundred years the balance in the social status has shown no privileges for nobility in birth; on the other hand, the decline in moral values and lack of 'gentlemanly behavior' has had a negative effect on social life. When the cultural markers of the concept are compared through their realization in the novels of three centuries, a simple deduction can be made that the gentleman has lost his central position in English culture and history. The concept GENTLEMANLINESS has been modified over the ages but it held values which were understood and admired. In the modern times, the reputation of the concept GENTLEMANLINESS has almost faded away, but to be called a gentle and kind man has never lost its importance.

\section{Works Cited}

Altmann, Gabriel. "The nature of linguistic units". Journal of Quantitative Linguistics. No. 3 (1996):1-7. Print.

Austen, Jane. Pride and Prejudice. London: Penguin Books, 1994. Print.

Collins, Wilkie. The Woman in White. London: Penguin Books, 1996. Print.

Evans, Vyvyan. Cognitive Linguistics: An Introduction. Edinburgh: Edinburgh University Press, 2006. - $830 \mathrm{p}$.

Evans, Vyvyan. Glossary of Cognitive Linguistics. Edinburgh: Edinburgh University Press, 2007. Print.

Fillmore, Charles. "Frame semantics and the nature of language". Annals of the New York Academy of Sciences: Conference on the Origin and Development of Language and Speech. Volume 280 (1976): 20-32. Print.

Firth, John Rupert. Papers in linguistics, 1934-1951. Oxford : Oxford University Press, 1957. Print.

Hoey, Michael. Lexical Priming. London: Routledge, 2005. Print.

Karasik, Vlodimir. Language Circle: personality, concepts, discourse. Moscow: Gnozis, 2004. Print 
Kononova, Inna. "Transformation of Cultural Concepts within the Concpetual Sphere of a Literary Text (on the Material of the Short Story by R. Bradbury "The Smiling People")". Journal of Siberian Federal University. Humanities and Social Sciences 12 (2015): 2868-2874. Print.

Lakoff, George and Johnsen, Mark. Metaphors We Live By. Chicago: The University of Chicago Press, 2003. Print.

Langacker, Ronald. Foundations of Cognitive Grammar. Vol 1. Standford: Standford University Press, 1987. Print.

Levytskiy, Victor. Quantitative Methods in Linguistics. Chernovtsy, 2004. Print

Peacocke, Christopher. A Study of Concepts (Representation and Mind). Colorado: A Bradford Book, 1995. Print.

Popper, Karl. "Normal Science and its Dangers". Criticism and the Growth of Knowledge. Eds. Imre Lakatos \& Alan Musgrave. 51-85. Cambridge: Cambridge University Press, 1970. Print.

Radbil, Timur. Basics of Language Mentality Studies. Moscow: Flinta, 2010. Print

Rosch, Eleanor. Reclaiming cognition: The primacy of action, intention and emotion. The Journal of Consciousness Studies, 6(1999.): 61-77. Print.

Sapir, Edward. "The Status of Linguistics as a Science". Language 5 (1929). Quoted in Selected Writings in Language, Culture, and Personality. University of California Press, 1992. Print.

Slyshkin, Gennadiy. Linguo-Cultural Concepts of Precedent Texts. Moscow: Academia, 2000. Print

Stepanov, Yuriy. Concepts. A Thin Cover of Civilization. Moscow: Languages of Slavic Cultures, 2004. Print

Stepanov, Yuriy. Methods and Principles of Modern Linguistics. Moscow : Libricom, 2009. Print

The Living Webster Encyclopedic Dictionary of the English Language. Ed. by Dama F. Kelerman. - Chicago : The English-Language Institute of America, 1993.Print.

Vorkachev, Sergey. "Cultural Concept and Meaning". Works of Kuban State Technological University. 268-276. Krasnodar: University Press, 2003. Print

Whorf, Benjamin Lee. Science and Linguistics.Massachusetts: MIT Press, 1940. Print.

Wittgenstein, Ludwig. Philosophical Investigations. Trans. G.E.M Anscombe. London: Basil Blackwell, 1953. Print. 